\title{
Variability in Care Management Programs in Medicare ACOs: A Survey of Medical Directors
}

\author{
Karen Donelan, ScD, EdM ${ }^{1,2}$, Esteban A. Barreto, $M S^{7}$, Carie U. Michael, $S M^{7}$, Peter Nordby, $M A^{3}$, \\ Maureen Smith, MD, MPH, $P h D^{3}$, and Joshua P. Metlay, MD, PhD ${ }^{1,2}$
}

'Massachusetts General Hospital, Boston, MA, USA; ${ }^{2}$ Department of Medicine, Harvard Medical School, Boston, MA, USA; ${ }^{3}$ University of WisconsinMadison School of Medicine and Public Health, Madison, WI, USA.

$\mathrm{J}$ Gen Intern Med 33(12):2043-5

DOI: $10.1007 / \mathrm{s} 11606-018-4609-1$

(c) Society of General Internal Medicine 2018

\section{INTRODUCTION}

The quest to reduce costs and readmissions has given rise to system- and practice-level approaches to identifying and managing the care of high-cost, high-risk populations. ${ }^{1}$ Care management programs (CMPs) have been developed in US health systems to connect nurses, social workers, and/or other staff with patients to coordinate care, reduce utilization, and lower costs, but evidence of success in cost reduction is variable. ${ }^{2,} 3$ Early models featured registered nurses as care managers, although more recent reports show models led by social workers. ${ }^{4}$ We aimed to develop approaches to classifying models of care management in Medicare ACOs that included staffing, CMP process, and outcomes.

\section{METHODS}

The data reported here come from a survey completed in a secure web-based survey tool by medical directors or clinical leaders of 15 care management programs in 2017. The sites were members in the Great Plains Collaborative (GPC) and the Scalable Collaborative Infrastructure for Learning Healthcare System (SCILHS), in the PatientCentered Outcomes Research Network (PCORnet). CMP leaders were recruited by email through referral by site principal investigators to identify a "care or case management program for high cost or high utilizing Medicare beneficiaries or other populations." Our questionnaire was developed through interviews with clinicians, patients, and administrators in CMPs; key domains include program structure, staffing, services, and outcomes. Question and response wording are shown in the tables.

\section{RESULTS}

Of 20 sites contacted, 18 responded; 3 sites did not have CMPs; at 2 non-respondent sites, a website search did not

Published online July 27, 2018 identify any existing care management programs. Table 1 shows program characteristics. Most programs provide a range of services; all have an RN or APRN on staff; most also have a social worker. Care managers in 12 programs interact directly with patients in hospitals or ambulatory offices, and 8 make home visits. High variability is seen in the annual and current number of cases served by the program, as well as in the typical caseloads per full-timeequivalent care manager.

Table 2 shows respondent reports of program outcomes as well as responses to attitudinal measures about program communication. Most programs use cost and utilization data to identify patients and track outcomes. Only one respondent "strongly" agreed their system had "finely tuned" their case-selection methodology. The most common program metrics include 30-day readmission rates and emergency utilization. While most agreed on the importance of "direct interaction of care managers with primary care providers," only 2 rated care managers' interactions with PCPs as "excellent." Other ratings of "excellent" were rare for communications and work relationships.

\section{DISCUSSION}

We surveyed medical directors of care management programs for high cost, high utilizing patients in 20 ACOs in two large networks that collectively cover approximately 25 million patients in 13 states. We cannot be certain about the generalizability of these findings outside of these two extensive networks. We surveyed medical directors of programs; we acknowledge that care managers, nurse, or social work leaders might report differently on attitudinal measures. These data show widely variable CMP process and structures that made classification challenging. Care management programs are a rapidly expanding as part of population health management strategy; few have realized cost savings. ${ }^{2}$ More research to understand the role of staffing, duration of service, and caseloads might inform future analyses of program effectiveness ${ }^{5}$ and return on investment. The relatively low level of use of patient reported 
Table 1 Program Characteristics $(n=15$ Programs)

\begin{tabular}{|c|c|}
\hline Year program launch, mean (S.D.) & $2012(3.8)$ \\
\hline Median (range) & $\begin{array}{l}2013 \\
(2003-2017)\end{array}$ \\
\hline $\begin{array}{l}\text { How many cases are currently being served by } \\
\text { your }\end{array}$ & $\begin{array}{l}7257(11694) \\
2150\end{array}$ \\
\hline $\begin{array}{l}\text { program? Mean (S.D.) } \\
\text { Median (range) }\end{array}$ & $(70-40,000)$ \\
\hline In the past 12 months, how many cases were served & $6564(8413)$ \\
\hline by your program? Mean (S.D.) & 2750 \\
\hline Median (range) & $(100-28,000)$ \\
\hline $\begin{array}{l}\text { In the past month, what is typical case load per care } \\
\text { manager? Mean (S.D.) }\end{array}$ & $\begin{array}{l}315(693) \\
90(16-2500)\end{array}$ \\
\hline Median (range) & \\
\hline $\begin{array}{l}\text { How long do cases typically stay active or open in } \\
\text { your program? }\end{array}$ & $N$ \\
\hline$\leq 3$ months (90 days) & 2 \\
\hline $3-6$ months & 4 \\
\hline $6+$ months & 8 \\
\hline No answer & 1 \\
\hline \multicolumn{2}{|c|}{$\begin{array}{l}\text { What is the educational background of the people who provide } \\
\text { care or case management services in your program? } \\
\text { (CHECK ALL THAT APPLY) }\end{array}$} \\
\hline $\mathrm{RN}$ & 14 \\
\hline Medical social worker & 11 \\
\hline APRN/PA & 7 \\
\hline MD (other than director) & 6 \\
\hline Community health worker, navigator & 9 \\
\hline Certified care manager & 3 \\
\hline Other (pharmacist, LPN, medical assistant) & 5 \\
\hline \multicolumn{2}{|l|}{$\begin{array}{l}\text { How do care/case managers interact with patients? } \\
\text { (CHECK ALL THAT APPLY) }\end{array}$} \\
\hline Telephone & 14 \\
\hline Text messages & 2 \\
\hline Clinical office visits & 12 \\
\hline Home visits & 8 \\
\hline Skype, Facetime, or other live virtual chat & 0 \\
\hline $\begin{array}{l}\text { Secure messaging through patient portal or } \\
\text { application }\end{array}$ & 7 \\
\hline Email outside of patient portal & 1 \\
\hline \multicolumn{2}{|l|}{$\begin{array}{l}\text { In your program, are the following services or assistance } \\
\text { provided to patients? (YES/NO EACH ITEM) }\end{array}$} \\
\hline $\begin{array}{l}\text { Initial intake/triage to assess needs and match to } \\
\text { program services }\end{array}$ & 14 \\
\hline Deciding goals of care with patient and family & 13 \\
\hline Assistance scheduling medical visits & 14 \\
\hline $\begin{array}{l}\text { Treatment and referral plans for complex chronic } \\
\text { conditions that are not well controlled }\end{array}$ & 13 \\
\hline $\begin{array}{l}\text { Arranging for financial assistance with needs such } \\
\text { as food, clothing, housing, and health care costs }\end{array}$ & 12 \\
\hline $\begin{array}{l}\text { Assistance arranging help with performing } \\
\text { activities of daily living }\end{array}$ & 9 \\
\hline Teaching patient/family about disease management & 13 \\
\hline $\begin{array}{l}\text { Care coordination at care transitions between } \\
\text { hospital and other facilities }\end{array}$ & 13 \\
\hline $\begin{array}{l}\text { Care coordination to assure primary care follow-up } \\
\text { after stay in hospital or other facility }\end{array}$ & 14 \\
\hline $\begin{array}{l}\text { Care coordination at care transitions from hospital } \\
\text { or other facility to home }\end{array}$ & 12 \\
\hline $\begin{array}{l}\text { Monitoring cases to prevent emergency visits or } \\
\text { high cost utilization }\end{array}$ & 12 \\
\hline Arranging transportation to visits & 10 \\
\hline Assistance with medication management & 14 \\
\hline Assessment of physical safety at home & 12 \\
\hline $\begin{array}{l}\text { Assessment of social support at home from } \\
\text { family and friends }\end{array}$ & 12 \\
\hline $\begin{array}{l}\text { Screening for depression, anxiety, or substance } \\
\text { abuse disorders }\end{array}$ & 12 \\
\hline $\begin{array}{l}\text { Screening for social determinants of health } \\
\text { such as food insecurity and housing insecurity }\end{array}$ & 11 \\
\hline Support or educational groups & 8 \\
\hline Remote monitoring of health conditions & 6 \\
\hline
\end{tabular}

measures and lack of uniformity in other outcome measures across programs was discouraging. Improving the
Table 2 Data for Identifying Patients and Measuring Quality ( $n=15$ Programs)

\begin{tabular}{ll}
\hline \hline How are patients identified? (CHECK ALL THAT APPLY) & $N$ \\
Patients are identified by health system based & 12 \\
on cost or utilization algorithm & 6 \\
$\begin{array}{l}\text { Patients are identified by health plan/payor based } \\
\text { on cost or utilization algorithm }\end{array}$ & 12 \\
Patients are referred by primary care providers & 10 \\
Patients are referred by hospital discharge planning & \\
or case management &
\end{tabular}

Patients or families self-refer

Within your care management program do you measure program outcomes in any of the following areas? (CHECK ALL THAT APPLY)

30-day readmission rates among patients in your program

Emergency visits by patients in your program

Health care costs incurred by patients in your program

Efficiency and cost-effectiveness (avoiding waste)

Patient-centeredness and experience

Effectiveness (providing or arranging services based

on scientific evidence and knowledge)

Access to healthcare for patients without insurance or with limited resources

Patient safety (avoiding injuries and errors)

Equity (providing care that does not vary in quality

because of demographic characteristics of the patient)

Timeliness of care (reducing waits and sometimes

harmful delays)

For each of the following items, please indicate whether you have analyzed data demonstrating that your program: (yes (definitely plus somewhat))

Increases coordination of services for patients

Decreases the costs of health care in your system

Decreases the cost of care that patients and families pay

Improves quality of life for patients

Rate your level of agreement with the following

(strongly agree, agree)

We have finely tuned our methods of identifying patients who need our care management program

Care managers can be most effective if they are working within a primary care office or clinic with other health care providers It is important for care managers to meet in-person periodically with patients in our program]

Rate quality of ....(excellent, very good, good, fair, poor)

Work relationships among care management staff from different professions such as medicine, nursing, and social work (excellent, very good)

Communication between program staff and primary care providers (excellent, very good)

Communication between care managers in hospital and ambulatory care (excellent, very good)

Communication between program staff and home care or long-term care professionals (excellent, very good)

12
11
8
7
7
4
3
3
2
2

2

12

11

7

$=$

2

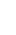

(1)

Y)

(1)

range of outcomes beyond utilization to include patient and stakeholder experience is essential to understanding the best processes to achieve those outcomes and the value of these programs.

Acknowledgements: The work benefitted from the advice and comment of patient stakeholder partners Mari Pat Berry, MA, Nancy Davin, and Aliaa Barakat, $P h D$.

Corresponding Author: Karen Donelan, ScD, EdM; Department of MedicineHarvard Medical School, Boston, MA 02115, USA (e-mail: kdonelan@mgh.harvard.edu).

Funding Information The research reported in this article was partially funded through a Patient-Centered Outcomes Research Institute (PCORI) Award (HSD-1603-35039). This project was also supported by the UW Health Innovation Program through the UW 
School of Medicine and Public Health Wisconsin Partnership Program, and the Community-Academic Partnerships core of the University of Wisconsin Institute for Clinical and Translational Research (UW ICTR) through the National Center for Advancing Translational Sciences (NCATS) (grant UL1TR000427).

\section{Compliance with Ethical Standards:}

Conflict of Interest: The authors declare that they do not have a conflict of interest.

Disclaimer: The views in this publication are solely the responsibility of the authors and do not necessarily represent the views of the PCORI, its Board of Governors, or Methodology Committee. The content is solely the responsibility of the authors and does not necessarily represent the official views of the NIH.

\section{REFERENCES}

1. Hong CS, Abrams MK, Ferris TG. Toward increased adoption of complex care management. $N$ Engl $J$ Med. 2014;371(6):491-493. https://doi.org/ 10.1056/NEJMp1401755.

2. McWilliams JM, Chernew ME, Landon BE. Medicare ACO program savings not tied to preventable hospitalizations or concentrated among high-risk patients. Health Aff. 2017;36(12):2085-2093. https://doi.org/ 10.1377/hlthaff.2017.0814.

3. Hsu J, Price M, Vogeli C, et al. Bending the spending curve by altering care delivery patterns: the role of care management within a pioneer ACO. Health Aff. 2017;36(5):876-884. https://doi.org/10.1377/hlthaff.2016. 0922.

4. Rowe JM, Rizzo VM, Shier Kricke G, et al. The Ambulatory Integration of the Medical and Social (AIMS) model: a retrospective evaluation. Soc Work Health Care. 2016;55(5):347-361. https://doi.org/10.1080/00981389. 2016.1164269 .

5. Ganguli I, Orav EJ, Weil E, Ferris TG, Vogeli C. What do high-risk patients value? Perspectives on a care management program. J Gen Intern Med. 2017:1-8. https://doi.org/10.1007/s11606-017-4200-1. 